\title{
Effect of the material's stiffness on stress-shielding in osseointegrated implants for bone-anchored prostheses: a numerical analysis and initial benchmark data
}

\author{
PIOTR PROCHOR $^{1 *}$, LAURENT FROSSARD ${ }^{2-5}$, EUGENIUSZ SAJEWICZ ${ }^{1}$ \\ ${ }^{1}$ Institute of Biomedical Engineering, Faculty of Mechanical Engineering, \\ Bialystok University of Technology, Białystok, Poland. \\ ${ }^{2}$ Your Research Project Pty Ltd., Brisbane, QLD, Australia. \\ ${ }^{3}$ Griffith University, Gold Coast, QLD, Australia. \\ ${ }^{4}$ University of the Sunshine Coast, Maroochydore, QLD, Australia. \\ ${ }^{5}$ Queensland University of Technology, Brisbane, QLD, Australia.
}

\begin{abstract}
Purpose: This study attempted to establish the link between design of implants for bone-anchored prostheses and stress-shielding, affecting the stability of the bone-implant coupling using numerical approach. The objectives were to share a numerical model capable to evaluate the long-term stability of implants and to use this model to extract data sets showing how shape and material stiffness of threaded, press-fit and modular press-fit implants affect stress-shielding intensity. Methods: Three designs were considered: threaded, press-fit and modular press-fit. The effect of shape and material stiffness of each design on stress-shielding intensity was assessed using Young's modulus (10 to $210 \mathrm{GPa}$ ). Furthermore, the impact of the diameter of percutaneous part (10 to $18 \mathrm{~mm}$ ) and thickness of medullar part $(5$ to $1 \mathrm{~mm})$ was investigated for the modular press-fit implant. Results: The threaded design generated $4 \%$ more bone mass loss at the distal femur but an overall loss of bone mass was by $5 \%$ lower to press-fit design. The influence of Young's modulus on bone mass changes was noticeable for modular press-fit implant, depending on diameter of percutaneous or medullary part. A 20 GPa change of stiffness caused a bone mass change from $0.65 \%$ up to $2.45 \%$ and from $0.07 \%$ up to $0.32 \%$ for percutaneous parts with $18 \mathrm{~mm}$ and $10 \mathrm{~mm}$ diameter, respectively. Conclusions: Results suggested that threaded implant provides greater stability despite an increased bone loss at the distal femur. Altogether, this work provided an initial model that could be applied in subsequent studies on the long-term stability of current and upcoming implants.
\end{abstract}

Key words: Young's modulus, bone mass, bone remodelling, osseointegration, bone-anchored prosthesis

\section{Introduction}

To date, gait for individuals with lower limb loss is most frequently restored using socket-suspended prostheses [3]. Despite a broad range of constructs and material solutions, sockets are yet to be fully satisfactory in many cases (e.g., short residuum, skin damages due to socket/skin interface) [1]. They present challenges associated with interface with the residuum's skin, unnatural control over the prosthesis, gait asymmetry or lack of proprioception [3].

Alternatively, some of these shortcomings could be alleviated by an osseointegrated fixation for direct attachment of a bone-anchored prosthesis [2], [10], [22], [26]. All commercial fixations currently available feature two typical parts [20]: an inner or medullar part (MP) inserted into the bone that must remain solidly attached upon completion of osseointegration process, and an outer or percutaneous part (PP) with

\footnotetext{
* Corresponding author: Piotr Prochor, Institute of Biomedical Engineering, Faculty of Mechanical Engineering, Bialystok University of Technology, ul. Wiejska 45A, 15-351 Białystok, Poland. Phone: +48 502-575-276, e-mail: p.prochor@pb.edu.pl

Received: March 16th, 2020

Accepted for publication: March 20th, 2020
} 
a proximal end positioned into the MP and a distal end protruding the skin of the residuum to enable external attachment of the prosthesis.

Over the last decades, the development of fixation has evolved essentially around two types of designs: threaded and press-fit [20]. Currently, the most acknowledged commercial fixation has screwtype design that is FDA-approved since July 15, 2016. A range of other fixations relying on press-fit design, comparable to implants used for joint reconstruction, are becoming increasingly popular, but yet to be FDA-approved.

Recent studies have demonstrated some clinical benefits of direct skeletal attachment (e.g., avoiding skin irritation problems, more natural control over prosthesis, hip range of motion, osseoperception) [8], [20]. However, in addition of breakage of fixation parts, adverse occurences, such as loosening, infection and periprosthetic fractures, remained to be satisfactorily resolved. Typically, these issues could derive from a poor fixation stability following a reduction of bone tissue density and thinning of bone layers around the implant.

This, so-called, stress-shielding effect is well described in the literature evaluating hip stems. Fundamental research focusing on material properties considers several ways to reduce the intensity of stressshielding. One of the most common interventions involves optimising the shape of the implant until efficient stem profile is achieved. The implantation of a safe and efficient implant should ensure more natural load transfer from the implant to the bone tissues, stimulating bone remodelling [24], [25].

Another way to reduce stress-shielding is to rely on current materials or possibly create new ones with relatively low stiffness [20]. The use of material characterized by low stiffness can further improve load transfer from the implant on the bone tissues. Hence, the recent attempts to design modular press-fit implants for direct skeletal attachment of limb prosthesis with the MP directly in contact with the bone tissue characterized by the Young's modulus (YM) closer to the bone's YM, while the PP remains stiffer to yield strength requirements (e.g., application of loads higher than bodyweight) [25]. Interestingly, several numerical and experimental studies confirmed that stress-shielding effect increases with osseointegrated implant material's stiffness [28].

Currently used materials, meeting strength, biocompatibility and biofunctional conditions, are mostly characterized by high stiffness [19]. Several materials have been used in implants for bone-anchored prostheses, including, but not limited to, Co-Cr-Mo alloys, commercial pure titanium, Ti-6Al-4V, stainless steel and glass-reinforced PEEK [11], [25]. However, it is necessary to consider materials, used in numerous implant constructs, characterized by a different stiffness and, therefore, potentially valuable to osseointegrated fixations [19]. Some individual YM values of materials commonly used in several types of medical implants are presented in Fig. 1 (e.g., dental implants, hip stems) [19], [25]. Stress-shielding around implants for bone-anchored prostheses has been reported mainly for small case-series studies [25], [28]. For this reason, their outcomes might be hardly generalisable, particularly when trying to estimate the stability of newly designed implants.

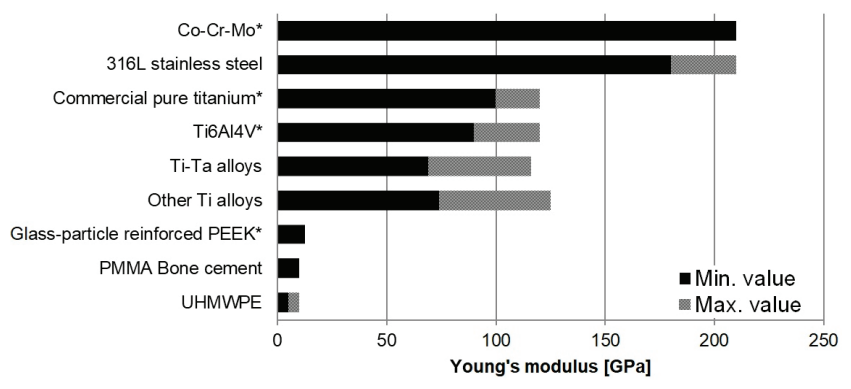

Fig. 1. Examples of selected materials currently used for medical implants ranked by Young's modulus values, including materials used in implants

for direct skeletal attachment of limb prosthesis $\left(^{*}\right)$

Most of previous finite element analyses of implants for bone-anchored prostheses focused on evaluation of individual constructs including specified dimensions, implant's shape or material properties [22], [23], [25], [28]. Although valuable when considering newly designed implants, the outcomes of these studies are partially transferable, as the results refer to particular and not general cases. Currently, there are no studies that considered various $\mathrm{YM}$ which could provide valuable insight into evaluation of efficiency and safety of new implants' designs. Therefore, there is a clear need for a better understanding of the impact of material's stiffness and generic design on stressshielding intensity of implants for direct skeletal attachment of a prosthesis.

The long-term goal of this study was to improve basic understanding of the efficacy and safety of osseointegrated implants for bone-anchored prostheses. The purpose was to establish a quantitative link between implant design and stress-shielding intensity affecting the stability of bone-implant coupling. The primary objective was to share a numerical model capable to evaluate long-term stability of implants considering a variety of shapes and material stiffness. 
The secondary objective was to use this model to determine how variations in shapes and material stiffness of threaded, press-fit and modular press-fit implants affected intensity of stress-shielding. We paid a particular attention on effects of variations in diameters of MP and PP of modular press-fit implant since most of newly developed implants for boneanchored prostheses rely on this design [20].

\section{Materials and methods}

\subsection{Analysed material and construction features of implants}

First, the influence of the YM value of the press-fit and threaded implants' material on the intensity of stress-shielding was evaluated. A total of $11 \mathrm{YM}$ values from $10 \mathrm{GPa}$ to $210 \mathrm{GPa}$ with an increment of $20 \mathrm{GPa}$ were considered, based on the range of the materials' parameters presented in Fig. 1.

Then, the influence of aforementioned changes in material properties was evaluated for modular press-fit implant including separate range of stiffnesses for MP and PP. As detailed in Table 1, we considered a total of 55 combinations of material stiffness for MP and PP ranging from 10 to $190 \mathrm{GPa}$ and from 30 to $210 \mathrm{GPa}$, with an increment of $20 \mathrm{GPa}$, respectively. To provide appropriate transfer of loads through the implant and reduction of stress-shielding, only the combinations of materials in which the YM value of the PP's material is higher than YM of the MP were analysed. For the same reason, we investigated the effect of changes in thickness of the MP ranging from 1.0 to $5.0 \mathrm{~mm}$ with an increment of $1.0 \mathrm{~mm}$.
Table 1. Overview of 55 combinations of material stiffness with Young's modulus for percutaneous and medullar parts ranging from $30 \mathrm{GPa}$ to $210 \mathrm{Gpa}$ and $10 \mathrm{GPa}$ to $190 \mathrm{GPa}$, with an increment of $20 \mathrm{GPa}$, respectively

\begin{tabular}{|c|c|c|c|c|c|c|c|c|c|c|}
\hline $\begin{array}{l}\text { Percutaneous } \\
\text { part's Young's } \\
\text { modulus [GPa] }\end{array}$ & 210 & 190 & 170 & 150 & 130 & 110 & 90 & 70 & 50 & 30 \\
\hline \multirow{10}{*}{$\begin{array}{l}\text { Medullar part's } \\
\text { Young's modulus } \\
\text { [GPa] }\end{array}$} & 190 & 170 & 150 & 130 & 110 & 90 & 70 & 50 & 30 & 10 \\
\hline & 170 & 150 & 130 & 110 & 90 & 70 & 50 & 30 & 10 & - \\
\hline & 150 & 130 & 110 & 90 & 70 & 50 & 30 & 10 & - & - \\
\hline & 130 & 110 & 90 & 70 & 50 & 30 & 10 & - & - & - \\
\hline & 110 & 90 & 70 & 50 & 30 & 10 & - & - & - & - \\
\hline & 90 & 70 & 50 & 30 & 10 & - & - & - & - & - \\
\hline & 70 & 50 & 30 & 10 & - & - & - & - & - & - \\
\hline & 50 & 30 & 10 & - & - & - & - & - & - & - \\
\hline & 30 & 10 & - & - & - & - & - & - & - & - \\
\hline & 10 & - & - & - & - & - & - & - & - & - \\
\hline
\end{tabular}

\subsection{CAD and FE models}

The CAD models were created using SolidWorks2017 software (Dassault Systéms). The implants were placed in the femur of an adult man, cut in half of its length to reflect post-amputation conditions. Implants were created with press-fit and threaded designs using the generic dimensions commonly provided in the literature to facilitate comparisons of the outcomes [4], [18]. Both types of implants were modelled considering the following dimensions: the length of the implant $=100.0 \mathrm{~mm}(80 \mathrm{~mm}$ for threaded design $)$, the outer diameter of the implanted part $=20.0 \mathrm{~mm}$, the diameter of the femur's shaft $=32.0 \pm 2.0 \mathrm{~mm}$, the diameter of the medullary cavity $=16.0 \pm 2.0 \mathrm{~mm}$, and the bone length $=237.5 \mathrm{~mm}$. We placed the threaded implant $20 \mathrm{~mm}$ within in the bone shaft, as suggested in the literature [22].
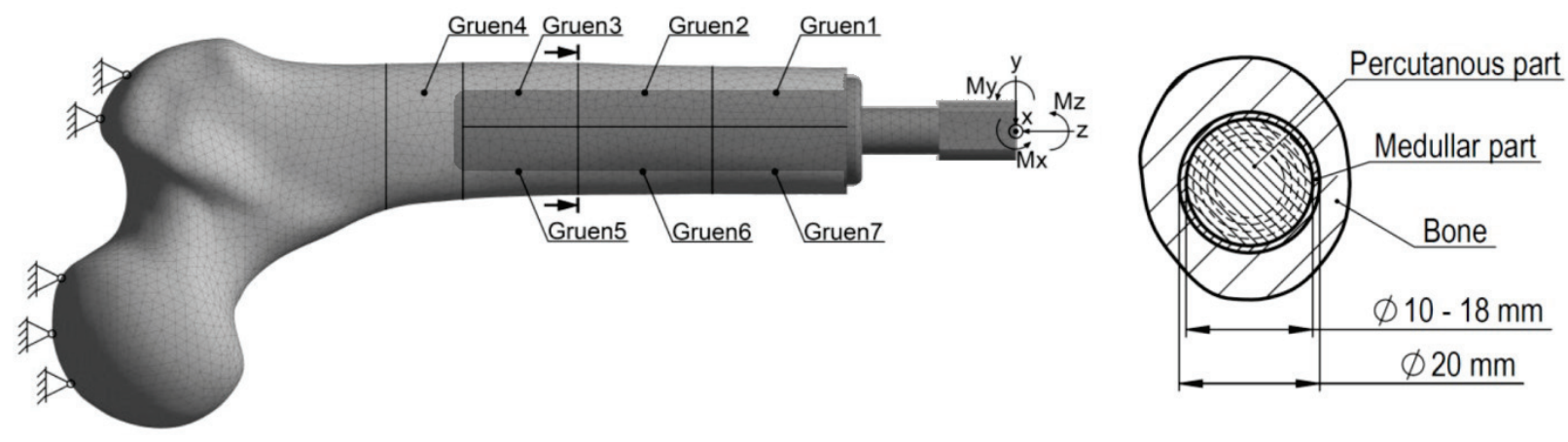

Fig. 2. Left: implant-bone model, considered boundary conditions, coordinate system adapted for the research and analysed Gruen zones; right: cross-section of the femur's shaft and the diameters of the medullar and percutaneous parts considered for press-fit implant 
The finite element models were created in Ansys Workbench v16.2 software (Ansys, Inc.). The discretisation was carried out using solid 10-node finite elements with a maximum edge length of $3.0 \mathrm{~mm}$ and $5 \%$ convergence test for Huber-von Mises stress. The models contained $125 \pm 15$ thousand finite elements. Supports were placed on the greater trochanter and femur's head (Fig. 2). A full osseointegration of the implant with the bone was considered by sharing the nodes of the implant and the bone at the place of their contact.

We extracted loading datasets from observational studies with participants fitted with a threaded implant, similarly to the bone remodelling study presented by Tomaszewski et al. [13], [14], [25]. Forces $(F)$ and moments $(M)$ applied on mediolateral (ML), anteroposterior (AP) and long axes (LG) of the fixation were extracted at heel strike and toe-off, as presented in Table 2 corresponding the Load 1 and 2 in Fig. 3, respectively.

Table 2. Magnitude of forces $(F)$ and moments $(M)$ applied on mediolateral (ML), anteroposterior (AP) and long axes (LG) of the fixation during heel strike (Load 1) and toe-off (Load 2) extracted from observational studies with participants fitted with a threaded implant presented by Lee et al. [13], [14]

\begin{tabular}{|l|c|c|c|c|c|c|}
\hline & \multicolumn{2}{|c|}{$\mathrm{AP}$} & \multicolumn{2}{c|}{ ML } & \multicolumn{2}{c|}{ LG } \\
\cline { 2 - 7 } & $F_{x}[\mathrm{~N}]$ & $M_{x}[\mathrm{Nm}]$ & $F_{y}[\mathrm{~N}]$ & $M_{y}[\mathrm{Nm}]$ & $F_{z}[\mathrm{~N}]$ & $M_{z}[\mathrm{Nm}]$ \\
\hline $\begin{array}{l}\text { Load 1 } \\
\text { Heel strike) }\end{array}$ & 100.0 & 30.8 & -20.0 & -7.2 & 780.0 & -2.0 \\
\hline $\begin{array}{l}\text { Load 2 } \\
\text { (Toe-off) }\end{array}$ & 120.0 & 37.3 & 40.0 & 4.1 & 180.0 & 0.0 \\
\hline
\end{tabular}

The stress-shielding intensity determining internal bone remodelling was also simulated using Ansys software (Ansys, Inc.). The appropriate batch files were prepared using the ANSYS Parametric Design Language (APDL). Internal bone tissue remodelling has been simulated by changing bone density. The dependency developed by Carter and Hayes was used to take into account the influence of bone density on its mechanical properties, presented in Eq. (1) [4].

$$
E=3790_{\rho}^{3}[\mathrm{MPa}]
$$

The bone mechanical properties were continuously updated during the calculation process using an appropriate subroutine developed in Fortran language. The strain energy density was used as a bone remodelling stimulus while considering the so-called lazy zone, corresponding to a range of stimulus values in which tissue is not stimulated to remodel, as presented in Eq. (2) [16].

$$
\frac{d \rho}{d t}=\left\{\begin{array}{l}
B\left(\frac{U}{\rho}-(1-s) k\right) \text { if } \frac{U}{\rho}<(1-s) k \\
0 \text { if }(1-s) k \leq \frac{U}{\rho} \leq(1+s) k \\
B\left(\frac{U}{\rho}-(1+s) k\right) \text { if } \frac{U}{\rho}>(1+s) k
\end{array}\right.
$$

The constants were respectively: $B=1.0\left[\mathrm{~g} / \mathrm{cm}^{3}\right]^{2} /$ $\left[\mathrm{MPa} / \mathrm{CTU}^{-1}\right], s=0.1, k=0.004[\mathrm{~J} / \mathrm{g}]$, where $B$ regulates the rate of bone remodelling process, $s$ regulates lazy zone width and $k$ regulates threshold value. Variables were $U\left[\mathrm{~J} / \mathrm{cm}^{-3}\right]$ and $\rho\left[\mathrm{g} / \mathrm{cm}^{-3}\right]$, where $U$ is strain energy density and $\rho$ is local bone density.

The strain energy density and the local bone density were calculated individually for each finite element included in the bone fragment. The mechanical properties of each finite bone element were adjusted at each step of the simulation process detailed in Fig. 3.

The mechanical properties of bone tissues were characterized considering densities of $1.740 \mathrm{~g} / \mathrm{cm}^{3}$ and

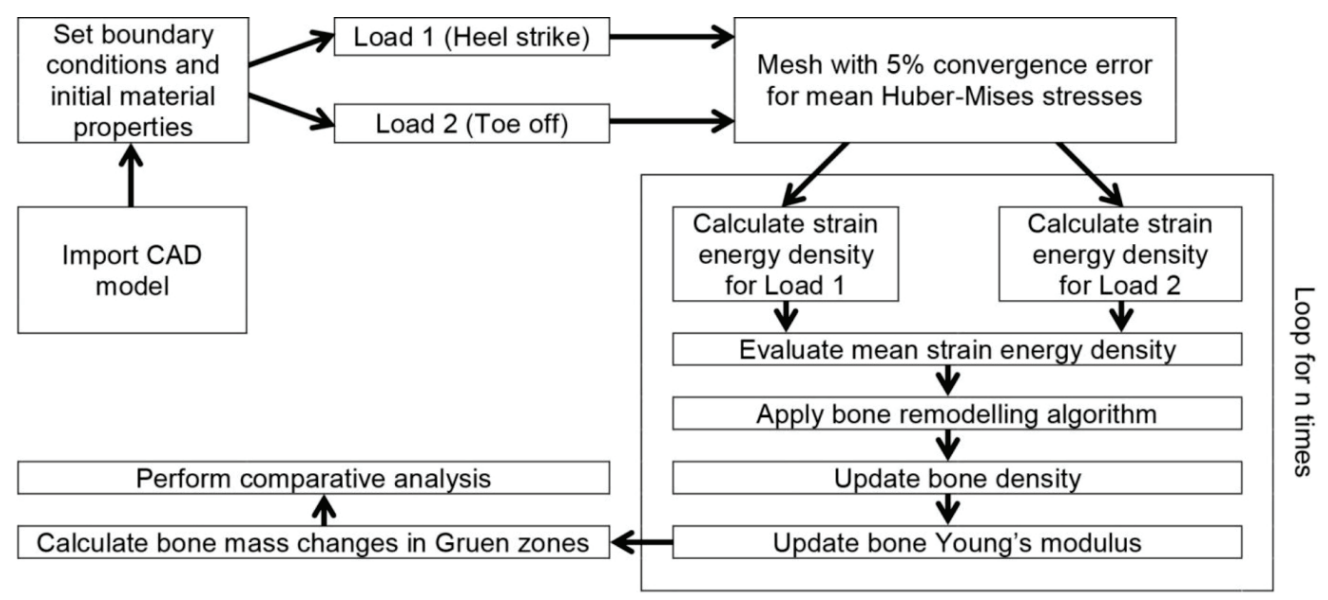

Fig. 3. Overview of the simulation process to determine long-term stability of implants considering a variety of implants shapes and material stiffness 
$0.630 \mathrm{~g} / \mathrm{cm}^{3}$ (YMs of $20 \mathrm{GPa}$ and $0.96 \mathrm{GPa}$ ) and constant Poisson's ratio of 0.30 and 0.12 for cortical as well as cancellous tissues, respectively. Maximum and minimum density thresholds were set at 2 and $0.2 \mathrm{~g} / \mathrm{cm}^{3}$, respectively [16].

We analysed bone mass (BM) changes in selected bone areas around the implant, using the Gruen zones (GZ) commonly considered [9], [17]. The results were adjusted to the clinical changes in bone density determined by $\mathrm{Xu}$ and Robinson [28]. The computation was first performed with a threaded implant considering the YM equal to $110 \mathrm{GPa}$, corresponding to the Ti6Al4V properties, until the closest similarity to observational studies [28]. It enabled us to define the number of computational loops occurring for the bone remodelling part of the algorithm presented in Fig. 3 that must be performed to directly reflect bone density changes presented in the literature [28]. After identifying the number of loops, the computation was continued for typical press-fit and modular press-fit implant required for the second part of the study. The analyses were purposely constricted to a 60 -month duration of implant loading, assuming that stabilisation following bone tissue remodelling process was achieved after that period [19].

\section{Results}

The outcomes of the first part of the analyses are presented in Fig. 4, including the evaluation of the influence of the YM of the press-fit and threaded implants on the intensity of stress-shielding effect. The stress-shielding intensity was presented as the change in BM in individual GZs (grouped in pairs, excluding GZ4, to allow easier comparison of opposite sections of the femur) as well as the general change in all zones at the same time, after 60 months of implant use.

A noticeable influence of implant's stiffness as well as its design on bone remodelling can be noticed. This effect can be observed in all nearly all analysed GZs apart from GZ4. The highest changes occur in distal part of the femur with the use of low (10 GPa) as well as high (210 GPa) YM.

The results of the second part of the research, i.e., the influence of the material's YM and the dimensions of appropriate elements of modular press-fit implant on the stress-shielding intensity, were presented as BM changes in all GZs simultaneously, as well as in individual GZs in Figs. 5-12. The higher the differences between the stiffness of PP and MP, the more intense changes in BM occurs.
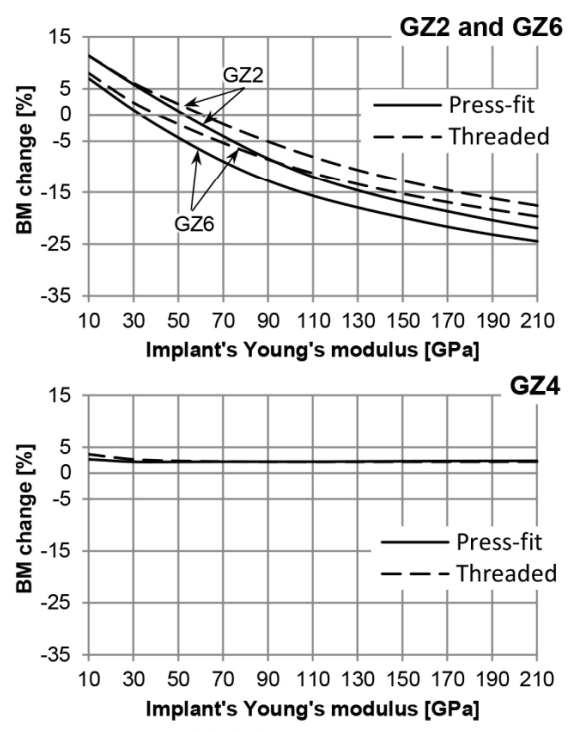

GZ1-7

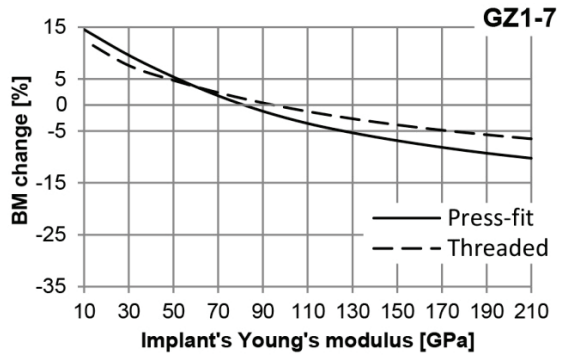

Fig. 4. Evolution of the bone mass (BM) in relation to Young's modulus for each of the Gruen zone (GZ) around the press-fit and threaded implants after 60 months 

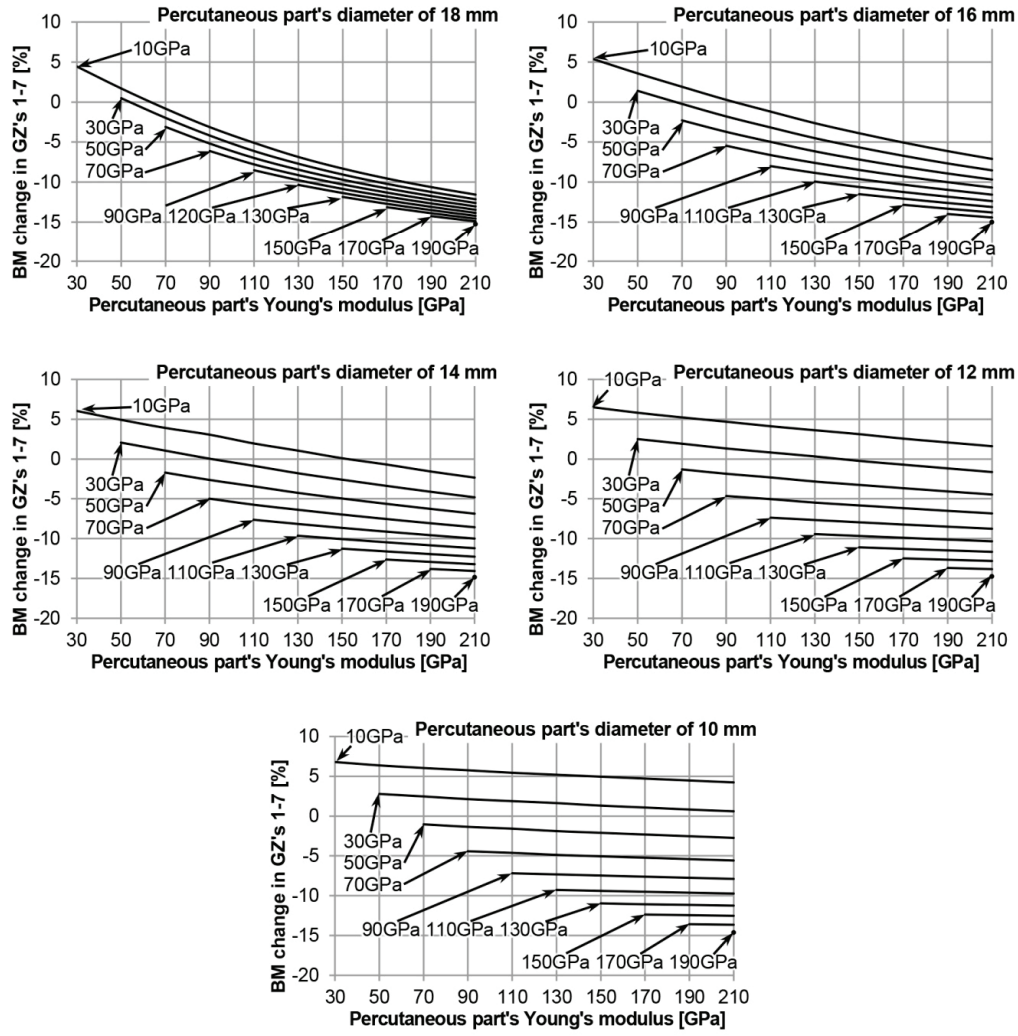

Fig. 5. The influence of Young's modulus of modular press-fit implant's material and the dimensions of percutaneous and medullar parts on the internal bone remodelling in all analysed Gruen zones (GZs) after 60 months; the arrows indicate the medullar part's Young's modulus
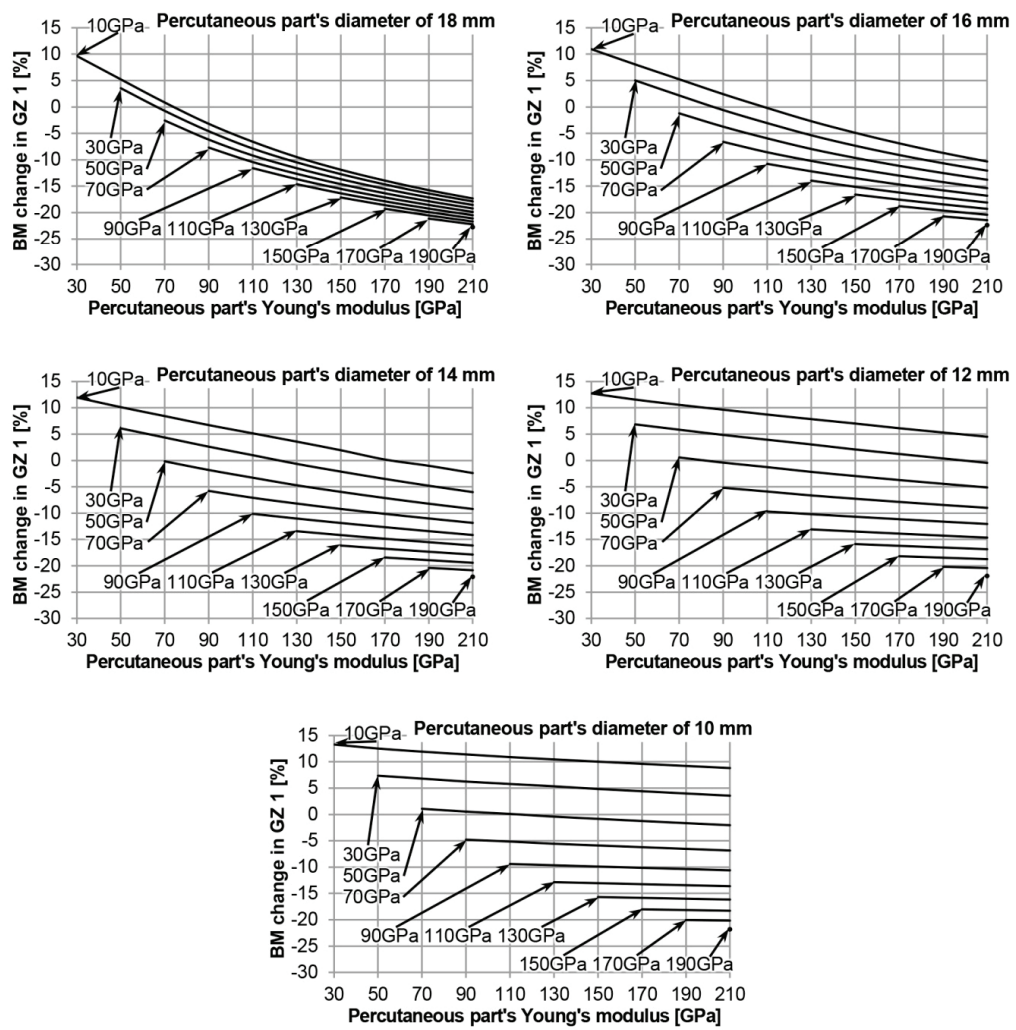

Fig. 6. The influence of Young's modulus of modular press-fit implant's material and the dimensions of percutaneous and medullar parts on the internal bone remodelling Gruen zone 1 (GZ 1) after 60 months; the arrows indicate the medullar part's Young's modulus 

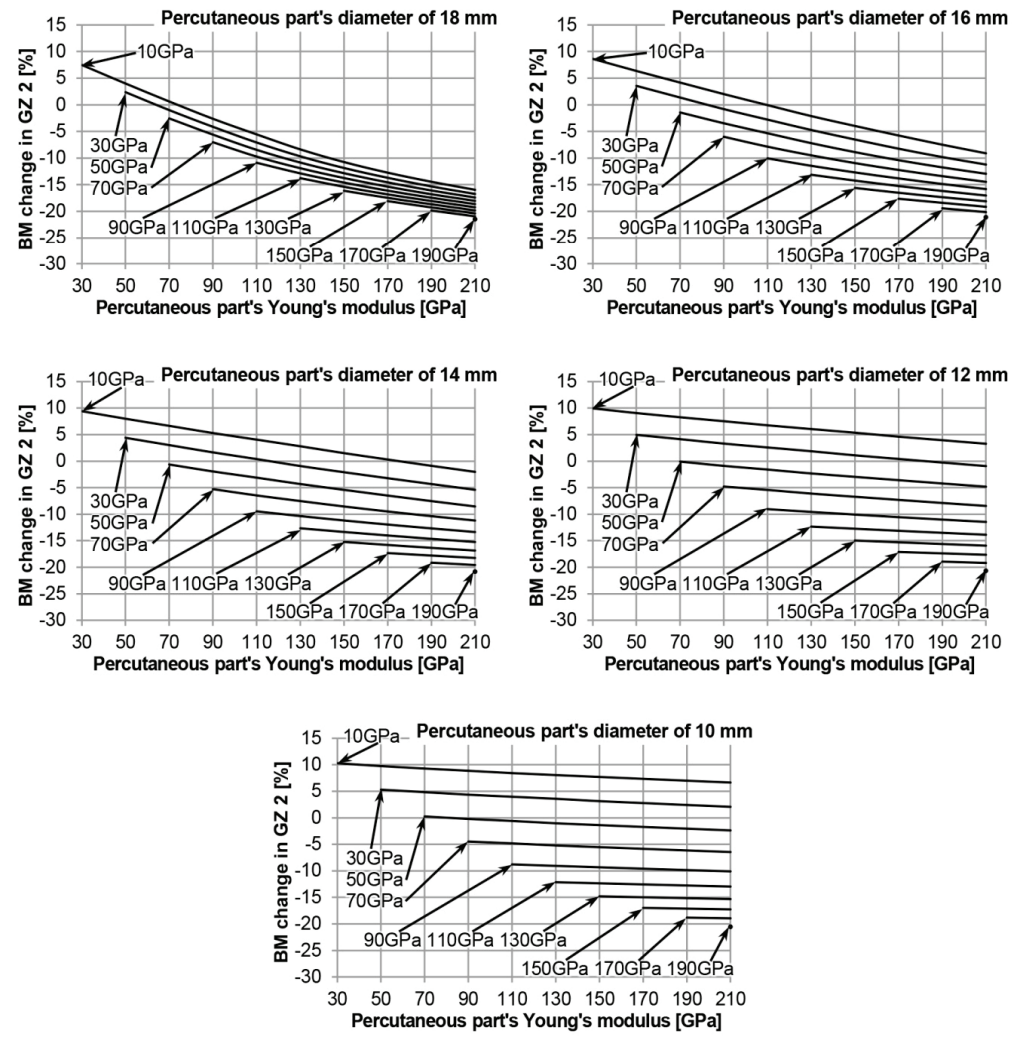

Fig. 7. The influence of Young's modulus of modular press-fit implant's material and the dimensions of percutaneous and medullar parts on the internal bone remodelling Gruen Zone 2 (GZ 2) after 60 months; the arrows indicate the medullar part's Young's modulus
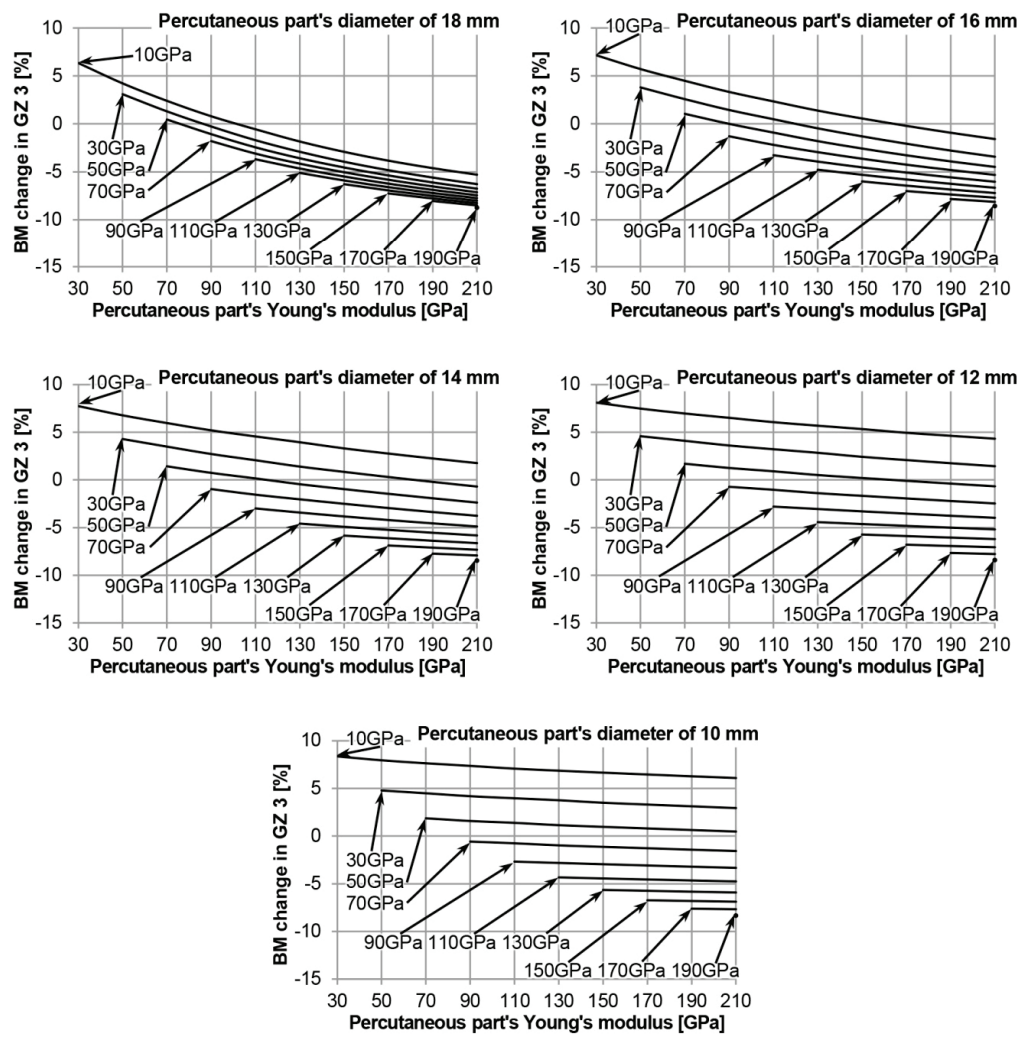

Fig. 8. The influence of Young's modulus of modular press-fit implant's material and the dimensions of percutaneous and medullar parts on the internal bone remodelling Gruen Zone 3 (GZ 3) after 60 months; the arrows indicate the medullar part's Young's modulus 

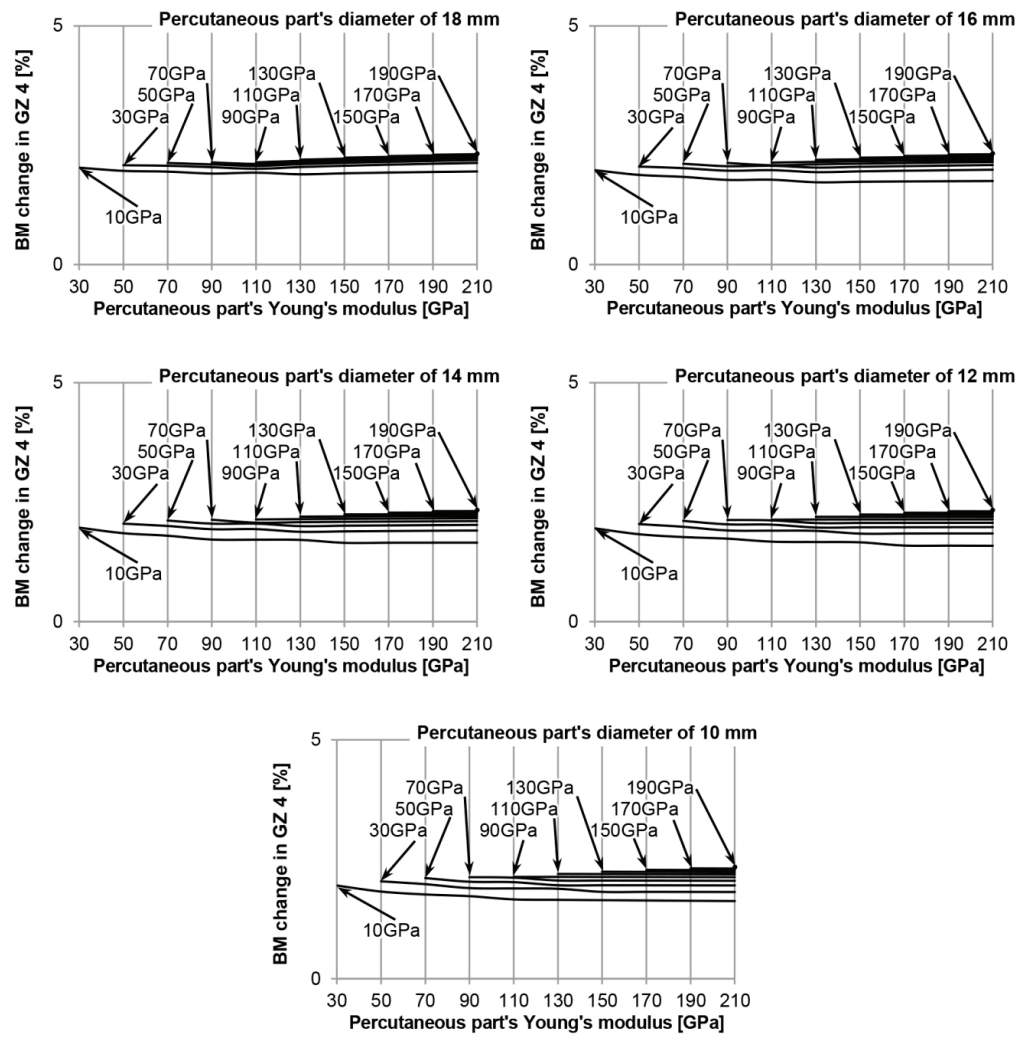

Fig. 9. The influence of Young's modulus of modular press-fit implant's material and the dimensions of percutaneous and medullar parts on the internal bone remodelling Gruen zone 4 (GZ 4) after 60 months; the arrows indicate the medullar part's Young's modulus
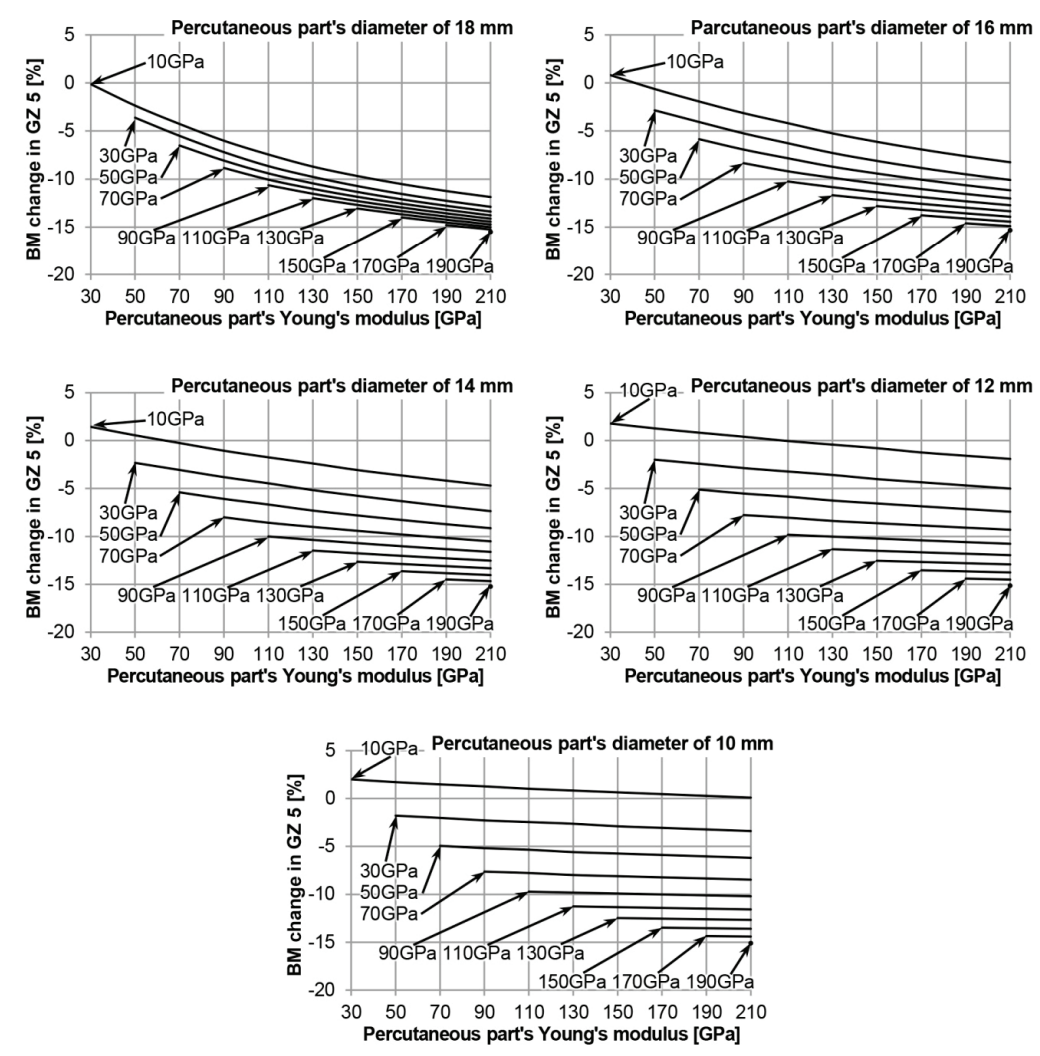

Fig. 10. The influence of Young's modulus of modular press-fit implant's material and the dimensions of percutaneous and medullar parts on the internal bone remodelling Gruen zone 5 (GZ 5) after 60 months; the arrows indicate the medullar part's Young's modulus 

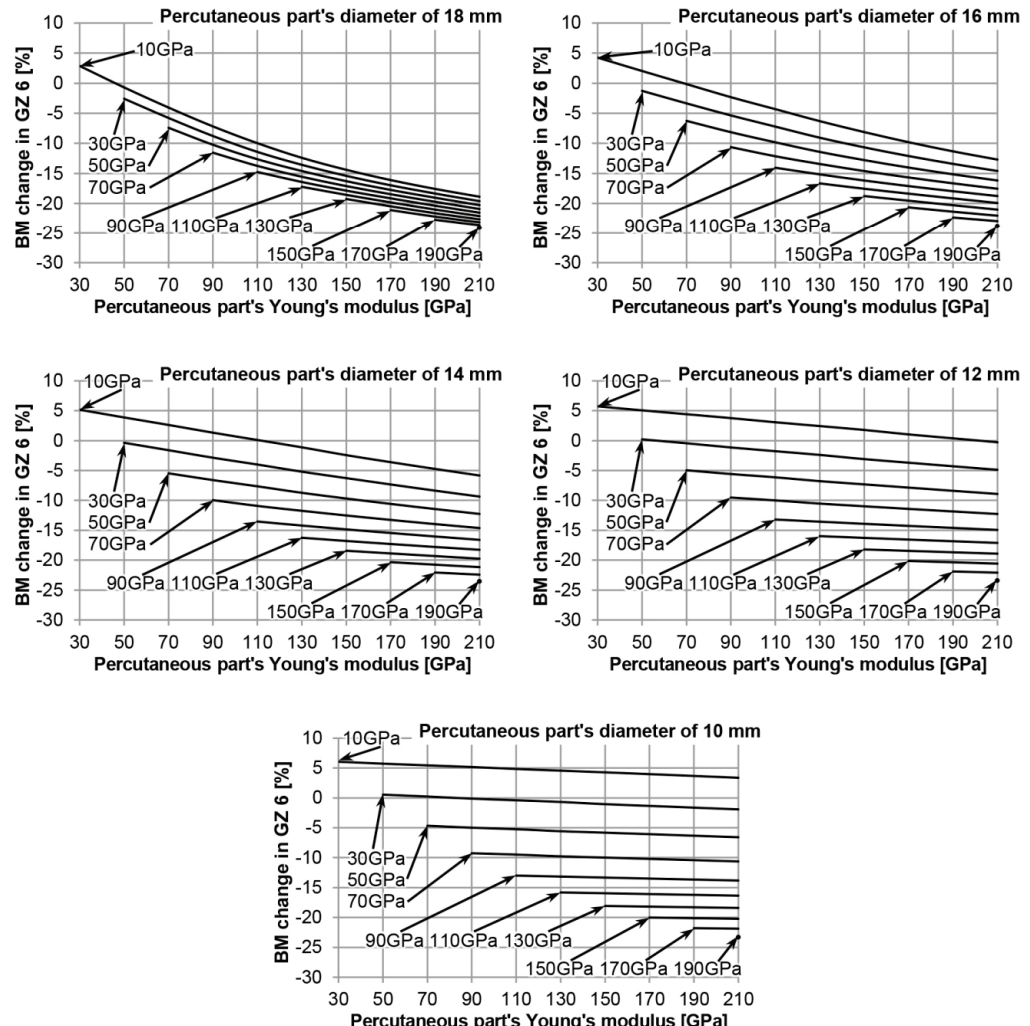

Fig. 11. The influence of Young's modulus of modular press-fit implant's material and the dimensions of percutaneous and medullar parts on the internal bone remodelling Gruen zone 6 (GZ 6) after 60 months; the arrows indicate the medullar part's Young's modulus
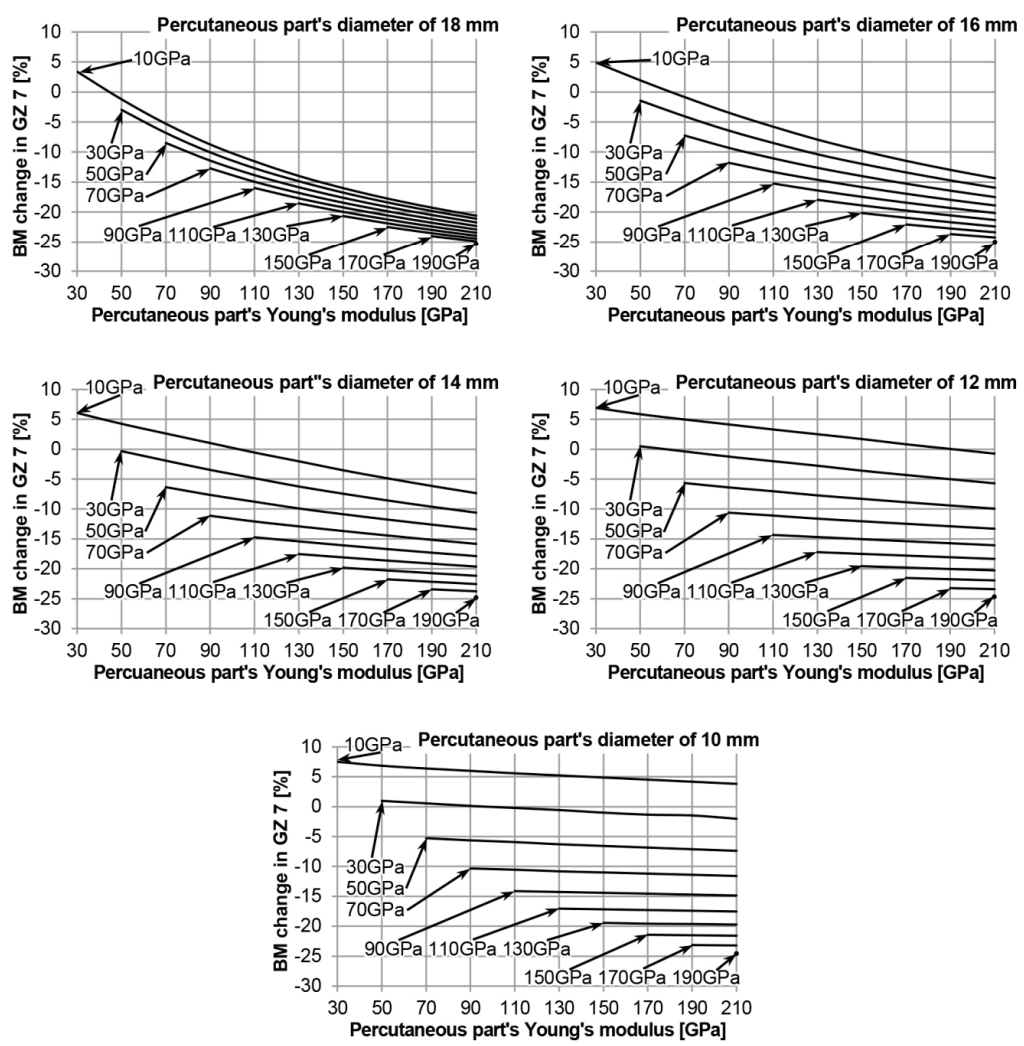

Fig. 12. The influence of Young's modulus of modular press-fit implant's material and the dimensions of percutaneous and medullar parts on the internal bone remodelling Gruen zone 7 (GZ 7) after 60 months; the arrows indicate the medullar part's Young's modulus 


\section{Discussion}

\subsection{The effect of Young's modulus of the implant's material on the stability of the press-fit and threaded designs}

The results suggested that the patterns of the progression between $\mathrm{BM}$ and constructional or material properties, tend to be nonlinear. The only exception was GZ4, where the changes in BM were consistent regardless of the change of material's YM. Moreover, the values were consistent while using press-fit or threaded solutions. Thus, an attempt to create a mathematical formula to describe the effect of shape and the considered parameters on stress-shielding intensity around the implants might be challenging.

GZ4 was the most proximal area of bone studied. Typically, this was a region of local concentration of stresses generated by the loads transmitted throughout the implant. It generated relatively constant bone remodelling stimulus, regardless of the material used for the implant. This confirmed a previous finding presented by Tomaszewski et al. [25], who reported growth in bone density in this zone.

Interestingly, there was a higher intensity of stress-shielding in the most distal zones of the implant (GZ1-7) after 60 months with a threaded implant $(\mathrm{GZ1}=-25.55 \%, \mathrm{GZ7}=-26.93 \%)$ compared to the press-fit implant (GZ1 $=-12.67 \%$, GZ7 $=-16.93 \%)$. These differences might be caused by the method of implantation of the threaded design, requiring insertion of an additional $20 \mathrm{~mm}$ within the medullary cavity [24].

For the remaining zones (GZ2, 3, 5 and 6), it can be noted that the change in BM was comparable for the threaded and press-fit implants at the time while applying the material with YM close to the bone's (10 $\mathrm{GPa}$ to $30 \mathrm{GPa}$ ). These differences gradually rise with the material's stiffness. With the use of material with YM up to circa 50-70 GPa, the bone shaft gains mass. However, when a material with a stiffness greater than $70 \mathrm{GPa}$ is used, bone density decreases due to the increased stress-shielding. Its intensity was lower in each of the above zones when using a threaded implant, which suggests a greater stability. Differences in BM loss were by about 2 to $5 \%$ in favour of the threaded implant. Variations in BM changes in the opposite GZs were the effect of the loads that cause the implant bending. This created asymmetrical distribution of bone remodelling stimulus, that is generated in the shaft of the femur.
Analysis of the total BM changes in all GZs showed the overall BM loss around the implant. It occurs only when the YM is higher than $90 \mathrm{GPa}$ (up to $-10.25 \%$ and up to $-6.51 \%$ for press-fit and threaded implants, respectively, while using the material with YM of $210 \mathrm{GPa}$ ). Furthermore, the intensity of stress-shielding was lower when using a threaded implant compared to press-fit implant. However, when using materials with a small YM (up to $50 \mathrm{GPa}$ ), bone density increases around the press-fit implant rather than around the threaded structure. For instance, while using the material with YM of $10 \mathrm{GPa}$, the changes were up to $14.54 \%$ and up to $12.49 \%$ for press-fit and threaded implants, respectively. Nevertheless, it should not noticeably affect the differences in the stability between both designs.

\subsection{The effect of Young's modulus of the implant's material and the percutaneous part diameter on the stability of the modular press-fit implant}

The results showed lowered stress-shielding intensity as PP's diameter decreased (increasing the MP's thickness). The differences were the highest with the greatest reduction of PP's diameter and with a material characterized by high stiffness (170 GPa up to $210 \mathrm{GPa}$ ) and low stiffness $(10 \mathrm{GPa}$ up to $50 \mathrm{GPa})$ on the MP. Smaller differences occur when using materials with similar YM (from circa 5\% to 10\%) on both PP and MP.

The effect of the analyzed parameters on the internal bone remodelling is noticeable in all GZs, excluding GZ4. BM changes in GZ1 ranged between -22.72 and $13.27 \%$ for PP with a diameter of $18 \mathrm{~mm}$ and YM of $210 \mathrm{GPa}$ (assuming MP with YM of $180 \mathrm{GPa}$ ) and PP with a diameter of $10 \mathrm{~mm}$ and $\mathrm{YM}$ of $30 \mathrm{GPa}$ (assuming MP with YM of $10 \mathrm{GPa}$ ), respectively. The BM changes obtained in the other GZs were noticeable, particularly for GZ2, GZ3, GZ5, GZ6 and GZ7 ranging between -21.46 and $10.29 \%$, -8.73 and $8.35 \%,-15.48$ and $1.99 \%,-24.06$ and $6.05 \%$ as well as $-25.30 \%$ and $7.50 \%$ (which were obtained with previously described parameters of MP), respectively. Interestingly, the most distal sections of the femur (GZ1 and GZ7) are characterized by higher $\mathrm{BM}$ increase compared to proximal GZs when materials with low stiffness are used. Relatively constant $\mathrm{BM}$ changes ranging between 2.34 and $1.95 \%$, regardless of the material or construction parameters 
used in the modular press-fit implant, occurred in the proximal GZ4.

In addition to the differences between individual GZs, the results also allow to estimate how the changes in YM as well as in diameter of PP and MP influence the internal bone remodelling. For PP with a diameter of $18 \mathrm{~mm}$, each change in YM by $20 \mathrm{GPa}$ causes changes in the BM ranging between 0.65 and $2.45 \%$. For the other diameters of PP (i.e., $16 \mathrm{~mm}$, $14 \mathrm{~mm}, 12 \mathrm{~mm}$ and $10 \mathrm{~mm}$ ), each change of PP's YM by $20 \mathrm{GPa}$ resulted in $\mathrm{BM}$ changes from 0.43 to $1.63 \%$, 0.26 to $1.01 \%, 0.15$ to $0.58 \%$ and 0.07 to $0.32 \%$, respectively.

\subsection{Interpretation of the results}

The results for threaded and press-fit designs, with material stiffness of $110 \mathrm{GPa}$ were similar to the ones shared by Tomaszewski et al. [25], who based their simulations on clinical results of bone remodelling process obtained by $\mathrm{Xu}$ and Robinson [28]. They have obtained bone mineral density change (assuming an immediate implantation), for example for GZ4 with a value of circa 3.35 and $2.06 \%$ for press-fit and threaded implants, respectively. The differences between implants considered by Tomaszewski et al. [25] might be due to length of the implant $132 \mathrm{~mm}$ for press-fit design. Increasing the length of the implant may also cause changes in the load transfer. By using the same generic dimensions, we have obtained similar
BM changes for both types of the analysed implants. Minor differences between the results of the authors with the data obtained by Tomaszewski et al. [25], may result from using a different bone model and bone remodelling concept as well as from a slightly longer remodelling period (50 months for Tomaszewski and 60 months in this study). Discrepancies might also appear due to the $20 \mathrm{~mm}$ insertion within the bone shaft we considered that was overlooked in Tomaszewski et al. [25]. The use of the above-mentioned insertion resulted in nearly complete lack of implantbone contact in GZ1 as well as GZ7, which prevents bone remodelling stimulation. This resulted in the BM changes in GZ7 of $10.4 \%$ higher intensity with threaded implant. A summary of differences in data of interest between this study and Tomaszewski et al.'s [25] as well as possible reasons was presented in Table 3.

Nevertheless, the results are generally characterized by similar values, suggesting that the data presented in this paper should properly reflect expected bone remodelling while using different types of implants with consideration of various implant's material stiffness.

The results of the second part of the study suggested that PP with high YM and MP with low YM provide appropriate bone remodelling. The following approach can lead to improving the strength parameters of the PP, which is the most vulnerable part to damage during the use of the implants considered here, according to the adverse events presented in the

Table 3. Differences between bone mass (BM) changes in Gruen zones (GZ) considering Young's modulus of $110 \mathrm{Gpa}$ for press-fit and threaded implants obtained in this study and presented in Tomaszewski et al. [25] and possible explanations

\begin{tabular}{|c|c|c|c|c|c|}
\hline \multirow[b]{2}{*}{ Implant } & \multirow[b]{2}{*}{$\mathrm{GZ}$} & \multicolumn{2}{|c|}{ BM changes in GZ [\%] } & \multirow[b]{2}{*}{$\begin{array}{l}\text { Possible differences } \\
\text { due to design }\end{array}$} & \multirow[b]{2}{*}{$\begin{array}{l}\text { Other possible } \\
\text { differences }\end{array}$} \\
\hline & & $\begin{array}{l}\text { Presented } \\
\text { results }\end{array}$ & $\begin{array}{c}\text { Tomaszewski } \\
\text { et al. [25] }\end{array}$ & & \\
\hline \multirow{7}{*}{ Press-fit } & 1 & -12.7 & -28.6 & \multirow{7}{*}{$\begin{array}{l}\text { Total length }(132 \mathrm{~mm} \\
\text { in [25] and } 100 \mathrm{~mm} \\
\text { in presented paper) }\end{array}$} & \multirow{14}{*}{$\begin{array}{l}\text { - Bone remodelling } \\
\text { concept } \\
\text { - Bone remodelling time } \\
\text { period } \\
\text { - Bone model } \\
\text { - Implants' positioning }\end{array}$} \\
\hline & 2 & -11.9 & -15.7 & & \\
\hline & 3 & -4.2 & -7.3 & & \\
\hline & 4 & 2.2 & 3.3 & & \\
\hline & 5 & -11.2 & -1.3 & & \\
\hline & 6 & -15.7 & -10.0 & & \\
\hline & 7 & -16.9 & -18.7 & & \\
\hline \multirow{7}{*}{ Threaded } & 1 & -25.5 & -25.6 & \multirow{7}{*}{$\begin{array}{l}\text { Additional insertion of the } \\
\text { implant by } 20 \mathrm{~mm} \text {; thread's } \\
\text { shape (no data presented } \\
\text { in [25]) }\end{array}$} & \\
\hline & 2 & -8.1 & -21.3 & & \\
\hline & 3 & -1.2 & -10.2 & & \\
\hline & 4 & 2.2 & 2.1 & & \\
\hline & 5 & -7.9 & -7.2 & & \\
\hline & 6 & -11.2 & -16.4 & & \\
\hline & 7 & -26.9 & -16.5 & & \\
\hline
\end{tabular}


literature [2], [11]. However, in this case, it should be remembered that the strength of the MP will be significantly reduced, which can be important during the long-term use of the implant. Altogether, this study confirmed that strength requirements, specific to each modular implant, to prevent failure due to impact and fatigue could be achieved by modulating the YM for MP and PP parts of the implant. For instance, MP made of material with a higher and lower YM can be used for MP and PP, allowing reduction in stressshielding intensity while maintaining strength parameters, respectively. However, additional numerical and experimental data must be collected to further verify this hypothesis.

\subsection{Limitation of the study}

The study presented the typical intrinsic limitations of numerical analyses of osseointegrated implants. Simplifications were made when characterizing stress-shielding of implants using the finite element methods. We used isotropic properties and homogeneity as input values for bone tissues. The influence of bacteria and body cells at the implant-bone interface was also discarded. External bone remodelling was ignored. We considered only the external forces and the moment applied of the distal end of the implant without considering stump's muscles forces. Only one concept of bone tissue remodelling was considered.

\subsection{Future studies}

Subsequent longitudinal studies could provide a more in-depth understanding of bone remodelling around osseointegrated implant for bone-anchored prostheses, particularly those using similar finite element models considering broader parameters such as: (1) skin ingrowth parts or prosthesis adapters that can influence implant loading method [20], [21]; (2) other level of amputation involving different bone and configuration load profile (e.g., transtibial amputation) [6], [7], [12], [15]; (3) in-bone positioning of the implant or its curvature, that often is adapted to bone's anatomical shape [20].

Additional cross-sectional studies could rely on the proposed finite element model to establish a link between bone remodelling and clinical recommendations during the course of the procedure including prescription of load bearing exercises and advanced prosthetic components [5], [27].

\section{Conclusions}

The outcomes suggested that the threaded implant reduces the intensity of stress-shielding in the proximal parts of the femur (GZ2, 3, 5 and 6). Press-fit implant might reduce BM loss in distal zones (GZ1 and 7) but increase stress-shielding in proximal zones, excluding GZ4. Part of the material and construction parameters' setups are difficult to apply in experimental conditions (i.e., YM of the implant lower than the $\mathrm{YM}$ of the bones). However, the results described how the implant-bone connection could behave in the long-term. Despite omitting strength of individual parts of the implant or the bone itself, the outcomes could be used to refine and evaluate efficiency and safety of commercial, newly designed and upcoming osseointegrated implants for bone-anchored prostheses.

\section{Acknowledgements}

This work was supported by the National Science Centre, Poland [grant number 2016/23/N/ST8/03526].

\section{Conflict of interest}

None.

\section{References}

[1] Abd RazaK N.A., Abu Osman N.A., Ali S., Gholizadeh H., WAN ABAS W.A.B., Comparison study of the prosthetics interface pressure profile of air splint socket and ICRC polypropylene socket for upper limb prosthetics, Biocybern. Biomed. Eng., 2015, 35 (2), 100-105.

[2] Atallah R., LeijendekKers R.A., HoOgeboom T.J., Frolke J.P., Complications of bone-anchored prostheses for individuals with an extremity amputation: A systematic review, PloS One, 2018, 13 (8), e0201821.

[3] BrÅnemark R., Berlin O., Hagberg K., Bergh P., GunTERBERG B., RYDEVIK B., A novel osseointegrated percutaneous prosthetic system for the treatment of patients with transfemoral amputation: A prospective study of 51 patients, Bone Joint J., 2014, 96-B (1), 106-113.

[4] CARTER D.R., HAYES W.C., The compressive behavior of bone as a two-phase porous structure, J. Bone Joint Surg. Am., 1977, 59, 954-962.

[5] Frossard L., HägGStröm E., Hagberg K., BrÅnemark R., Load applied on bone-anchored transfemoral prosthesis: characterization of a prosthesis - a pilot study, J. Rehabil. Res. Dev., 2013, 50 (5), 619-634.

[6] Frossard L., Leech B., PitKin M., Automated characterization of anthropomorphicity of prosthetic feet fitted to boneanchored transtibial prosthesis, IEEE Trans. Biomed. Eng., 2019, 66 (12), 3402-3410. 
[7] Frossard L., LeECh B., PitKin M., Inter-participant variability data in characterization of anthropomorphicity of prosthetic feet fitted to bone-anchored transtibial prosthesis, Data Brief, 2019, 25, 104195.

[8] Hagberg K., BrÅnemark R., Gunterberg B., Rydevik B., Osseointegrated trans-femoral amputation prostheses: prospective results of general and condition-specific quality of life in 18 patients at 2-year follow-up, Prosthet. Orthot. Int., 2008, 32 (1), 29-41.

[9] Haket L.M., Frölke J.P.M., Verdonschot N., Tomaszewski P.K., VAN De MeEnT H., Periprosthetic cortical bone remodeling in patients with an osseointegrated leg prosthesis, J. Orthop. Res., 2017, 35 (6), 1237-1241.

[10] Hebert J.S., Rehani M., Stiegelmar R., Osseointegration for Lower-Limb Amputation: A Systematic Review of Clinical Outcomes, JBJS Rev., 2017, 5 (10), e10.

[11] JuhnKe D.L., Beck J.P., JeYAPALina S., Aschoff H.H., Fifteen years of experience with Integral-Leg-Prosthesis: Cohort study of artificial limb attachment system, J. Rehabil. Res. Dev., 2015, 52 (4), 407-420.

[12] KhemKa A., Frossard L., Lord S.J., Bosley B., Al Muderis M., Osseointegrated total knee replacement connected to a lower limb prosthesis: 4 cases, Acta Orthop., 2015, 86 (6), 740-744.

[13] Lee W.C., Frossard L., Hagberg K., Haggstrom E., BrÅnemark R., Evans J.H., PeArCy M.J., Kinetics of transfemoral amputees with osseointegrated fixation performing common activities of daily living, Clin. Biomech., 2007, 22 (6), 665-673.

[14] Lee W.C., Frossard L., Hagberg K., Haggstrom E., Gow D.L., GRAY S., BRÅNEMARK R., Magnitude and variability of loading on the osseointegrated implant of transfemoral amputees during walking, Med. Eng. Phys., 2008, 30(7):825-833.

[15] LeiJendeKkers R.A., VAN Hinte G., FröLKe J.P., VAN DE Meent H., Atsma F., Nijhuis-van der SAnden M.W., HoOgeboom T.J., Functional performance and safety of bone-anchored prostheses in persons with a transfemoral or transtibial amputation: a prospective one-year follow-up cohort study, Clin. Rehab., 2019, 33 (3), 450-464.

[16] MartíneZ-Reina J., OJeda J., Mayo J., On the Use of Bone Remodelling Models to Estimate the Density Distribution of Bones. Uniqueness of the Solution, PLoS One, 2016, 11 (2), e0148603.

[17] Nebergall A., Bragdon C., Antonellis A., Kärrholm J., BrÅnemark R., Malchau H., Stable fixation of an osseointegated implant system for above-the-knee amputees: titel RSA and radiographic evaluation of migration and bone remodeling in 55 cases, Acta Orthop., 2012, 83 (2), 121-128.
[18] Newcombe L., Dewar M., Blunn G.W., Fromme P., Effect of amputation level on the stress transferred to the femur by an artificial limb directly attached to the bone, Med. Eng. Phys., 2013, 35 (12), 1744-1753.

[19] NiINOMI M., Recent metallic materials for biomedical applications, Metall. Trans A., 2002, 33, 477-486.

[20] PITKIN M., Design features of implants for direct skeletal attachment of limb prostheses, J. Biomed. Mater Res. A., 2013, 101, 3339-3348.

[21] Pitkin M,, Cassidy C., Muppavarapu R., Edell D., Recording of electric signal passing through a pylon in direct skeletal attachment of leg prostheses with neuromuscular control, IEEE Trans. Biomed. Eng., 2012, 59 (5)-13491353.

[22] Prochor P., Piszczatowski S., SAjewicz E., Biomechanical Evaluation of a novel Limb Prosthesis Osseointegrated Fixation System designed to combine the advantages of interference-fit and threaded solutions, Acta Bioeng. Biomech., 2016, 18 (4), 21-31.

[23] Prochor P., SAJewicz E., A comparative analysis of internal bone remodelling concepts in a novel implant for direct skeletal attachment of limb prosthesis evaluation: A finite element analysis, Proc. Inst. Mech. Eng. H., 2018, 232 (3), 289-298.

[24] Stenlund P., Trobos M., Lausmaa J., Brånemark R., THOMSEn P., PALmQuist A., Effect of load on the bone around bone-anchored amputation prostheses, J. Orthop. Res., 2017, 35 (5), 1113-1122.

[25] Tomaszewski P.K., Verdonschot N., Bulstra S.K., RietMan J.S., Verkerke G.J., Simulated bone remodeling around two types of osseointegrated implants for direct fixation of upper-leg prostheses, J. Mech. Behav. Biomed. Mater., 2012, 15, 167-175.

[26] VAN Eck C.F., McGough R.L., Clinical outcome of osseointegrated prostheses for lower extremity amputations: a systematic review of the literature, Curr. Orthop. Pract., 2015, $26(4), 349-357$.

[27] Vertriest S., Coorevits P., Hagberg K., BrÅnemark R., HÄGgStröm E., VAnderstraeten G., Frossard L., Static load bearing exercises of individuals with transfemoral amputation fitted with an osseointegrated implant: reliability of kinetic data, IEEE Trans. Neural Syst. Rehabil. Eng., 2015, 23 (3), 423-430.

[28] Xu W., Robinson K., X-ray image review of the bone remodeling around an osseointegrated trans-femoral implant and a finite element simulation case study, Ann. Biomed. Eng., 2008, 36 (3), 435-443. 